Culture et histoire dans l'espace roman

$6 \mid 2011$

Figures du pouvoir dans la littérature hispanoaméricaine

\title{
Figuras y reverberaciones del poder en las dramaturgias latinoamericanas
}

\section{Carlos Dimeo}

\section{(2) OpenEdition}

\section{Journals}

Edición electrónica

URL: https://journals.openedition.org/cher/9472

DOI: $10.4000 /$ cher.9472

ISSN: 2803-5992

\section{Editor}

Presses universitaires de Strasbourg

\section{Edición impresa}

Fecha de publicación: 30 junio 2011

Paginación: 191-201

ISBN: 978-2-35410-033-9

ISSN: 1968-035X

\section{Referencia electrónica}

Carlos Dimeo, «Figuras y reverberaciones del poder en las dramaturgias latinoamericanas», reCHERches [En línea], 6 | 2011, Publicado el 17 diciembre 2021, consultado el 25 enero 2022. URL: http://journals.openedition.org/cher/9472 ; DOl: https://doi.org/10.4000/cher.9472

\section{(c) (i) (2)(2)}

Ce(tte) œuvre est mise à disposition selon les termes de la Licence Creative Commons Attribution -

Pas d'Utilisation Commerciale - Partage dans les Mêmes Conditions 4.0 International. 


\title{
Figuras y reverberaciones del poder en las dramaturgias latinoamericanas
}

\author{
Carlos Dimeo \\ Universidad Maria Curie-Skłodowska - Lublin, Polonia
}

$\mathrm{E}$ teatro será siempre una definición, una construcción social, un sistema de representaciones. A través de éste podemos reconstruir los modos de representación de la cultura en distintos espacios y tiempos. La expresión propia del teatro hoy, está sumida desde su propio devenir, es decir: constelación y concatenación de elementos que se articulan a través de distintos modos de espectacularización. El teatro es la transparencia de la vida misma en el sentido de que habitamos en un mundo que está teatralizado casi en su totalidad. Decía Jean Genet que « el poder no funciona sin teatralidad». Para el autor de Severa vigilancia y Diario de un ladrón, la teatralidad usada como procedimiento en los mecanismos de poder, nos remite a la relación directa entre: teatro y vida, teatro y sociedad, teatro y mundo, teatro y política, teatro e ideología y aún más teatro y poder. Pero lo que más impacta de la relación entre el poder y el teatro, es el lazo que entre ellos establece la propia acción de lo teatral como procedimiento básico para el desarrollo de esto que llamamos: «Lo espectacular». El poder teatraliza cada una de sus acciones, le ofrece la dinámica propia de la “acción” escénica, de la acción física. Otorga a ello toda su representatividad, todo su peso. De esta manera, el poder inevitablemente se vuelve metateatral o en esencia misma se transforma en pura espectacularización. Surgen trueques, intercambios, redes: entre un "poder que se ha teatralizado»y la «teatralización del poder». Separar, delimitar esta geografía es una clave que hoy por hoy se hace imprescindible para definir al teatro. Entonces en

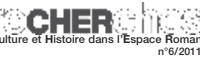


consecuencia de ello se hace necesario distinguir las relaciones entre: poder y teatro.

Teorías políticas y tesis sobre el poder para el estudio de ellas en el teatro

Algunas fuentes importantes quiero tomar como base y punto de partida para abordar el tema; y que desde el punto de vista teórico resultan necesarias perfilarse. Los destinos políticos del teatro en América Latina, digamos que van en tres vías, fundamentalmente y en primer lugar la de: Louis Althusser, partimos de sus textos La revolución teórica de Marx, Los aparatos ideológicos del estado y Marx dentro de sus límites y así contextualizamos una primera etapa del teatro en América Latina que toma el tema del poder.

Una segunda vía derivada de esta primera que se vincula a las definiciones sobre poder y política que nos ofrece Nicos Poulantzas en Fascismo y dictadura, pero especialmente de la aplicación de las técnicas y métodos de la Pedagogía del oprimido de Paulo Freire, fundamentados desde la poética de Agusto Boal en su Teatro del oprimido desarrollado hacia la década de los 70 y que se extendió como práctica escénica y actoral por todo el continente.

Una tercera y última que refiere a las tesis y definiciones que nos aporta Hannah Arendt, y toda la que se funda desde su teoría política, dependiendo a su vez de esta misma la de Walter Benjamin; Iluminaciones III: Tentativas sobre Brecht e Iluminaciones IV: Para una crítica de la violencia, la nave de los locos, la cual en definitiva marcan los nuevos derroteros del concepto de poder y política en el teatro.

\section{Dramaturgias políticas}

Los estudios que aquí presentamos intentan construir varios aspectos: en primer lugar hacemos una cierta y mínima genealogía del teatro político latinoamericano. Pero esta suerte de genealogía, no es - y no intenta referirse a - un estudio exhaustivo del mismo, son a nuestro entender, llamémoslo así: ciertos "excursus", algunas miradas sacadas con pinzas en relación con el teatro y el tema del poder: sus orígenes y sus textos fundacionales; aquello que constituyen para mi las fuentes primigenias de esas teatralidades.

El teatro puede funcionar como metáfora que defina de cuál manera se construyen los sistemas de relaciones de poder dentro y/o a partir de él. Pero no al contrario, si el poder utiliza lo teatral es porque le sirve o le funciona como máscara, como "transporter", como eje de transmisión, o lo que en 
la cultura de la magia llamamos "materia" o "medio para". El teatro es un "medio para" o "materia" en el campo del poder. Materia es un cuerpo que sirve de medio para transportar ciertos espíritus o lo que resulta inmanente en la esfera del poder. El poder simula, juega transparencias. El teatro es el mundo de transparencias, de juegos de espejos y representaciones mitológicas, históricas y políticas. La teatralidad es el escenario propicio del poder. Para el objeto de nuestra presentación, hemos abordado nuestro estudio desde dos perspectivas y hemisferios distintos.

\section{Teatro y Poder en dos tiempos}

\section{Cordelia de Pueblo en Pueblo de Alberto Adellach, Argentina. Escrita entre España, México y Estados Unidos. Premio Casa de Las Américas 1982}

Es la representación del poder por vía de la revolución. La revolución como mecanismo de transformación social y de las relaciones de poder entre los miembros de una sociedad. Alberto Adellach toma la obra inspirado en los personajes del Rey Lear de William Shakespeare pero la contextualiza en la Argentina de los años 60. A partir de allí transforma toda la trama del texto original, le interesa el valor interior de los personajes shakespereanos y su capacidad épica, de valor y sacrificio. La pieza únicamente ha sido estrenada una vez; la puesta estuvo a cargo del director Jaime Jaimes, en el año 1983. El estreno de la obra fue realizado por el grupo "Teatro Latino » en el Mission Cultural Centre de Los Ángeles, San Francisco en Estados Unidos. Es precisamente la censura que domina el poder en América Latina de los 70 la que prohibe su difusión y representación.

Las formas de presentarnos el tema del poder en esta pieza está centrado en exponer las relaciones de equilibrio social entre dos polos bien definidos y marcados, (lo que la teoría marxista llama burguesía y proletariado) y que según Poulantzas el marxismo plantea de ellas que debe haber coexistencia de ambas en equilibrio para que puedan subsistir. En el momento en el cual estas clases entran en conflicto, pasamos a una segunda etapa llamada de "equilibrio catastrófico" y a partir de allí se desarrollan según Poulantzas las formas de fascistización del poder. Pero, y aquí hay otro elemento importante, Poulantzas explica: «será la burguesía la que constituya el aspecto principal de la contradicción surgida entre burguesía y proletariado », es precisamente en este momento cuando se desatan las fuerzas que desencadenan un proceso revolucionario. 
De la misma forma que Poulantzas explica el desarrollo del conflicto entre ambas fuerzas, idénticamente Adellach en Cordelia de pueblo en pueblo estructura sus escenas. Progresivamente vemos cómo ambas clases, representadas de un lado por la troupe que dirige Lear y de otro lado por un empresario, un gerente, un intendente, un militar, etc., va haciendo hallazgos importantes que desencadenan en la conclusión de que la única salida para la transformación de poder es la vía "revolucionaria" o lo que se traduce como lucha armada. Adellach lleva poco a poco a ambos grupos representados en los personajes que antes mencionamos, para que entre ellos surja una sola salida y se desencadene un "equilibrio catastrófico " con la diferencia que en este caso el resultado no es una salida "fascista", sino revolucionaria, en conclusión: el triunfo es del "pueblo". El pueblo toma el poder sólo por la vía armada que es la consecuencia directa de todo proyecto revolucionario y que además sólo así y de esta manera podrá acceder a las formas del poder. De tal manera que: ¿qué representa esta idea del poder en Adellach? El poder se detenta sólo transformando la "realidad social". Entendiendo aquí a la realidad social, sólo como hecho "científico". La construcción dramática de Cordelia de pueblo en pueblo al final, es poner en voz de los desplazados, de los trashumantes (y en este sentido todo pueblo es un trashumante) los mensajes que deben llegar al público y que debe agitarse, actuar en la realidad. En otras palabras se justifican las tesis de Althusser y Poulantzas.

En general en América Latina todo estaba tramado a través de las construcciones del poder político, estaba tamizado por ello y el teatro que formó la generación de los grandes, también estuvo filtrado por ese contexto. Lo que todavía no queda muy demarcado es: si las prácticas teatrales (en el fondo formas de representación, de conservación y de elaboración de las prácticas sociales) habrían estado más vinculadas a temas del poder u otros temas. Los límites, las fronteras entre teatro y acción insurreccional es, a decir verdad, un campo inexplorado, no precisamente por la falta de estudios, sino porque delimitar hasta donde llega uno u otro resulta de sí mismo casi imposible, no se puede observar claramente las diferencias entre arte y agitación, arte y propaganda.

Esa geografía no se ha explorado aún, puesto que las urgencias sociales requerían de los artistas "acción política" y "acción creadora" más que reflexión sobre los procesos tanto políticos como de creación. Todo estuvo condicionado por esa encrucijada. El teatro pues fue más que en un proceso reflexivo sobre los actos y los hechos políticos, un fuerte mecanismo de acción sobre los acontecimientos políticos de la época, un medio que llevaba 
un fin determinado y específico: la información y la propaganda. De esta manera se hizo un teatro de agitación y un teatro político, se hizo un teatro con objetivos y trazos políticos, pero no referente a lo político, en relación a esto explica Enrique Revuelta, director de Teatro Estudio de Cuba:

Formulábamos un mensaje que en primer lugar había sido elaborado en forma más o menos colectiva, en el que lo teatral no se fijaba en normas demasiado rígidas, donde lo teatral se mezclaba o se hacía sobre la base de sketchs, de canciones, de espectáculo audiovisual, de consigna política.

Ese era el modelo sobre el cual se entablaban los puntos de partida de una ejecución teatral. El teatro abandonó lo que comúnmente ocupaba un lugar y espacio en los dominios de la estética, y se vinculó con la expresión de lo que fue el fin último del hecho escénico : la propaganda, «el panfleto». El teatro latinoamericano de estas décadas respondía a las tendencias propias del llamado movimiento de «agit-prop» (el teatro de agitación y propaganda). El teatro de Adellach no apunta a construir una teoría del "panfleto" político, más bien atiende a enfrentarse con determinadas zonas, determinados conceptos que implican un debate sobre el poder. Si el resultado de Cordelia de pueblo en pueblo es la toma de la fábrica y en consecuencia el desencadenamiento de una guerra de guerrillas en base a una teoría de la revolución, no es para informarnos sobre las maneras por las cuáles se debe acceder al poder. Por el contrario, lo que intenta Adellach, es impregnarnos de las formas que en los años setenta y ochenta se conflictuaba el poder, y desde donde se podrían suponer las fuerzas y fuentes de la resistencia. Es un planteo de desmesura, y un planteo de desmesura resulta en sí utópico. El único camino posible para la liberación será fruto de la revolución, como transformación total de una sociedad y como construcción de un modelo político latinoamericanista, que responda directamente a las necesidades propias del concepto.

\section{Antígona, versión libre de José Watanabe, para Yuyachkani 2000}

La versión de Watanabe supone una reflexión del poder en el mundo contemporáneo. Pero aquí la concepción del poder se mide desde otros caminos. Como primera medida distingamos que: la política pertenece al ámbito, al mundo "en vida", al mundo "de la vida", y no pertenece así a aquellos que están en el mundo de los muertos, o que ya han muerto. En consecuencia la política es un acto propio del vivir y no del morir. Se "es", y en consecuencia se es si se produce la relación: "ser-político-en-sí”, en tanto y 
en cuanto estamos en vida y sólo con los otros, intervenimos e interpelamos, o somos interpelados por otredades que configuran "el mundo".

De pronto, hemos sido y estamos arrojados en un mundo que posee un cierto sentido, y como tal ese sentido se vuelve o se torna político: sólo ante la vida, pues no precisamente como consecuencia ante la muerte. Tal cual, porque la vida pertenece a los que hemos sido arrojados al mundo de los vivos, y no así al mundo de los muertos. Arendt ya alerta que su teoría política se funda en el mundo del vivir. Hay política sólo a partir del nacimiento, cuando estamos en el mundo con los otros. El sentido de este mundo está otorgado pues, por todo aquello que han dejado los vivos al morir, al desvanecerse. Según Daniel Mundo por aquellos que al morir, al desaparecer de la compañía de los vivos, nos han dejado; un sentido a recordar, una tradición, un mundo con sentido. Los que nacen o están ya en el mundo (los que viven), perciben y discuten, si estas estructuras de orden pueden otorgarnos un marco de convivencia. Es especialmente en este ámbito donde se construye la política y por ello tiene que ver con el mundo de los vivos y no de lo muertos. Convivir es vivir con tus congéneres, según los cuáles sólo así, se "es", se "llega a ser". Para Hannah Arendt la política sólo puede "ser en" y "del mundo" de los vivos, porque consensúa y conflictúa: verdad y justicia, verosimilitud y juicio. Además de ello, son los perjuicios los que elaboran una dinámica de las acciones políticas y en consecuencia humanas, y cambian los rumbos de la convivencia.

La Antígona de José Watanabe fue escrita originalmente como un monólogo, de acuerdo con una petición hecha por el Grupo Yuyachkani de Perú, con el objetivo del grupo de retomar algunas ideas enmarcadas en las esferas del teatro político. Los valores de este texto son múltiples y complejos, uno de ellos y de los más difíciles de lograr es el uso de la poesía en el teatro, en la que Watanabe destaca la fuerza del tema del poder en relación con una mirada sobre la historia política del Perú. En este sentido, toca un tema que en los países del cono sur, Argentina, Chile, Paraguay, Perú y Bolivia, se constituyó como una poderosa estructura de conflictos sociales; esto fue: desapariciones forzadas, asesinatos y la creación de fosas comunes en las que se han hallado múltiples cadáveres sin reconocimiento y sin identificación, los llamados "NN». Por ello no es casual que Watanabe use sólo a una actriz, y que toda la historia sea contada desde un lugar femenino, porque la mujer en las luchas por el poder ha sido un factor determinante en la historia latinoamericana. 
De manera que el conflicto de la obra es el marco de la acción que allí se juega. La estructura dramática de este texto tiene dos hilos, a partir del mito de Antígona, Watanabe invierte las posiciones de orden en el juego de los personajes. En la historia original de Sófocles, Ismene es un personaje que resulta precisamente minimizado, convertida en pusilánime, frente a la fuerza y bravía de Antígona, pero en la obra de Watanabe esta fuerza se trueca y al final del texto descubrimos que el personaje de la narradora, que es además quien ha estado contando todos los embates que ha llevado Antígona a partir de su desafío al poder, es Ismene. E Ismene, no resulta tan pusilánime como Sófocles nos la ha puesto, sino que al contrario en la versión de Watanabe el personaje se vuelve fuerte y nos devela al final que ha sido ella quien ha robado la mascarilla mortuoria y quien se ha atrevido "silenciosamente" a desafiar el poder verdaderamente:

22.

\section{NARRADORA}

Las muertes de esta historia vienen a mí/ no para que haga oficio de contar desgracias ajenas./ Vienen a mí, y tan vivamente, porque son mi propia desgracia:/ yo soy la hermana que fue maniatada por el miedo./ Antígona entró en mi casa como un airado y súbito fulgor / y me habló así: «Ismene, / quiero que tus manos me ayuden a sepultar el cadáver de nuestro amado hermano,/ confío/ en que habiendo nacido noble/ no te haya ganado la villanía » / Sus palabras ardían, / pero yo tenía el ánimo como el de un pequeño animal encogido, / y sabiendo que le asistía razón, / le dije que deliraba, que un aire de locura le había golpeado la cabeza./ Era el miedo, Antígona, porque la muerte sería nuestro pago por enterrarle./ Ven, hermana, te rogué, mejor pidamos a los muertos que nos dispensen / y que prevalezcan sobre nosotras las órdenes de los poderosos vivos, / pero me reprochaste, dijiste: «busca tú, Ismene, / la aprobación del mundo del tirano, yo iré tras la gracia / de los dioses", y te fuiste / a la colina de nuestro muerto. / (Abre la caja que trajo al principio de la obra y descubre la mascarilla mortuoria de Polinices. La toma entre sus manos y hace el gesto de tres libaciones)/ Antígona, ¿ ¿ves este mundo de abajo? / El palacio tiene ahora un profundo silencio de mausoleo / y desde ahí nos gobierna un cadáver que respira, un rey/ atormentado/ que velozmente se hace viejo./ Hermana mía, mira:/ este es el rostro de nuestro hermano antes de los perros/ y los buitres y la podredumbre, / y estas libaciones tardías son de mi pequeña alma culposa. / En tu elevado reino / pídele a Polinices que me perdone la tarea que no hice a tiempo / porque me acobardó el ceño del poder, y dile / que ya tengo castigo grande:/ el recordar cada día tu gesto/ que me tortura/ y me avergüenza./ (estrella la mascarilla contra el piso y de la caja saca tierra que deja caer sobre los fragmentos).

Telón. 
Tal como se observa, la consumación de los efectos del poder se vuelcan en la tragedia griega, desde el ámbito de los dioses, pero en la tragedia contemporánea la muerte de los tiranos y el fin del poder no caduca y aquí en el texto de Watanabe parecemos encontrar el efecto más preponderante de ello. Si bien el poder de una sociedad no radica en la organización y estructura jerárquica de esa sociedad, la solución de Watanabe es plantearnos que el problema central de Antígona no es el de la civilidad, sino el del orden instituido, y que ese orden debe estar en concordancia con el espíritu del conjunto, de lo contrario derrocarlo. Por ello en la pregunta está el conflicto y lo trágico: ¿a quién podemos dejar sin sepultura? El mismo Creonte al desafiar a los ciudadanos de Tebas, pone fin a su voluntad de poder, lejos de afianzarse y demostrar su fuerza, lo que hace con esta acción es sustraer cada vez más sus espacios de dominio. Creonte ha ganado la guerra, ha logrado bajo ardides y trampas que Polinices y Etéocles se enfrenten y se quiten la vida entre sí, mutuamente. Todo ello parece augurarle larga vida en el gobierno de Tebas y en el trono, pero su obstáculo mayor radica precisamente en dejar el cadáver de Polinices expuesto al aire de la ciudad, condenar al "muerto" a un "no enterramiento", con lo cual se inicia la cadena de acontecimientos que desatará la destrucción de su poder. Al final Creonte se retracta de la orden de encarcelar a Antígona, puesto que se ve vencido, y logra dar cuenta que no ha sido Antígona quien ha robado la mascarilla mortuoria y quien ha rociado fino polvo sobre el cuerpo de Polinices. El texto último (anteriormente citado) y el texto del Guardia, así nos lo confirman:

GUARDIA

Qué difícil llegar hasta ti, rey, no por tus alturas en el poder/ sino por mi temor de darte el bocado que traigo./ Cuántas veces me he detenido en mi carrera/ porque el corazón me decía: "vuélvete, regresa, cuidado,/ que apenas dando la noticia, tú mismo la has de pagar»./ Con tales pensamientos / el camino corto me ha dado un viaje largo./ Sí, sé que estoy hablando para dilatar el tiempo mío / y sólo logro tu real impaciencia. / Sea entonces la noticia: anoche alguien ha sepultado a Polinices. / No, no es que el muerto esté acogido bajo la tierra,/ sino que le han frotado fino polvo sobre toda la piel. / El alguien inició así el rito del soterramiento, / pero la luz del alba lo hizo huir./ Guardias contra guardias nos hemos culpado, / pero será, te pregunto, negligencia de hombres si el desobediente de tu decreto/ fue un dios? / Ese pensamiento silenció de pronto nuestra discusión allá en la colina. / Señor, convendrás que quien llega y huye / deja huellas, / y no había ninguna, ni de rueda ni de pie ni de arañazo de azada. $/{ }_{¿}$ No te dice el corazón, como a nosotros, que el enterrador llegó por el aire/ o que no es de visible sustancia humana? 
Este debate lo lleva a derogar su ley, pero es muy tarde ya. Antígona se ha ahorcado, Hemón se dará muerte ante sus ojos, Tebas ve nuevamente sucumbir su poder y su estabilidad. Para terminar de enlazar la acción sólo hasta cuando al final hemos llegado a saber que la narradora quien ha venido contando nuestra historia es Ismene, resulta la única triunfadora de toda la historia. La fuerza del poder actúa en silencio, y sin que ninguno de los otros personajes la percibiera han sido conducidos a la derrota por su propia mano.

Existe un proverbio en español que reza: «La ambición es hija de mal padre», quiero decir que lo revelador de la metáfora creada por Watanabe está precisamente en ver que el silencio destruye al poder más omnímodo, pues mientras todos y cada uno de ellos se disputaban las pequeñas microfísicas jugadas en la escena, Ismene redime a su hermano Polinices, pero también a su hermano Etéocles (quienes se habían descuartizado mutuamente en el fragor de la batalla), en fin Ismene redime el valor de la tragedia edípica, ser hermana e hija a la vez, no tener trono por esa razón agonística que desencadena la fuerza de los dioses y que dejará a Edipo postrado en la mayor de las inquinas que hicieron de su vida, una vida miserable. El poder minimiza y oculta todo lo bueno, juega en los campos del inframundo, por ello en la muerte. Ismene redime al pueblo de Tebas. Después del «primer día de la paz» aún «las armas enemigas no han sido recogidas y están dispersas sobre el polvo como ofrendas inútiles». Ismene ha roto la mascarilla mortuoria y ha regado el fino polvo, el cadáver de Polinices yace ahora en el lugar correcto en el cual desde un principio debió haber estado. Los cauces han vuelto a su lugar, y las aguas permanecen quietas frente a la antigua Tebas, pero sólo hasta que los dioses se levanten nuevamente y abran las compuertas de las demoníacas fuerzas para que desaten ferozmente otra vez la lucha por el poder.

Es difícil y complejo asegurar que todavía haya un teatro que trate el tema del poder en América Latina, sobretodo cuando la cuestión sobre el poder se vuelve hoy singularmente difusa, dispersa, incontrolable. De tal modo que la pregunta por el poder en el teatro, surge inevitablemente en un doble sentido, esto es: ¿poder en el teatro?, ¿la teatralidad del poder?, ¿teatro y poder? Confrontación histórica en la que Arendt nos introduce, entre espacio público y espacio privado, la unción entre lo que ella misma llamaría: vita activa / vita contemplativa. Como la mayoría de las cosas figuradas en la modernidad, al teatro también se lo considera una fuerte actividad de carácter político que atenta contra las bases del poder constantemente. 
Política y poder de la que parece no podemos separarnos, algunos constatan que no hay teatro sin política, constatan que ningún teatro puede serlo si de alguna forma no se torna a lo político y a la política o las figuras y formas del poder. Es de suponer que la expresión más fuerte del teatro radica precisamente en su fuerte politicidad y politización, en la teatralidad del poder como antes aseguraba Jean Genet. Para el pensamiento moderno todo se torna o se vuelve un constante debate sobre el poder, en tanto es expresión de una cierta metafísica, lo que va constituyendo un sujeto es la actividad y su repercusión política, esto es: cada cosa que hago influye en los demás y por lo tanto el espacio escénico se torna provechoso para estos discursos. La forma de encarar las metáforas y las epistemes que rodean lo político cambiaron sus hipótesis centrales: el teatro ya no va a "la política", el teatro ahora, ahonda en "lo político" y en sus metáforas, es decir se vuelve metáfora destructiva, deconstructiva y constructiva de las teatralidades del poder y del poder de la teatralidad.

\section{Bibliografía}

Adellach, Alberto, 1974, Teatro. Buenos Aires: Ediciones del Tablado.

Althusser, Louis, 1972, Ideología Y Aparatos Ideológicos De Estado: Abril 1970, Grupos De Estudio De Filosofía Y Letras: Cuaderno. [s.l.] : Grupos de Estudio de Filosofía y Letras.

Althusser, Louis, 1990, La Revolución Teórica De Marx. [24a. ed, Biblioteca Del Pensamiento Socialista. Serie Ensayos Críticos. México [etc.] : Siglo XXI.

Althusser, Louis, 1967, La Revolución Teórica De Marx: Siglo XXI.

Althusser, Louis, 2003, Marx Dentro De Sus Límites, Cuestiones De Antagonismo. Madrid: Akal.

Baudrillard, Jean. La Transparencia Del Mal: Ensayo Sobre Los Fenómenos Extremos. [2a.ed.] ed, Argumentos. Barcelona: Anagrama, 1993.

Benjamin, Walter, 1975, Iluminaciones III: Tentativas Sobre Brecht. Madrid: Taurus.

Benjamin, Walter, 1982, Iluminaciones I: Para Una Crítica De La Violencia. 3a. ed ed, La Nave De Los Locos. México: Premía editora.

Boal, Augusto, 1974, Teatro Del Oprimido ; Y Otras Poéticas Políticas. Buenos Aires: Ediciones de la Flor.

Boutang, Pierre, y George Steiner, 1994, Diálogos, Sobre El Mito De Antígona Y El Sacrificio De Abraham. Barcelona: Destino.

Clementelli, Elena, Attilio Dabini, y Anna Scriboni, 1974, Teatro Latino Americano: 10 Atti Unici Di 8 Autori D'avanguardia. Roma: Instituto Italo-Latino Americano. 
Freire, Paulo, 1973, Pedagogía Del Oprimido. 8 ed, Educación. México [etc.]: Siglo Veintiuno.

Poulantzas, Nicos, 1979, Fascismo Y Dictadura: La Tercera Internacional Frente Al Fascismo. 4 ed, Sociología Y Política. Madrid: Siglo Veintiuno de España.

Sófocles, 1969, Antígona; Edipo Rey; Electra, Punto Omega. Madrid: Guadarrama.

Steiner, George, 2000, Antígonas: La Travesía De Un Mito Universal Por La Historia De Occidente. 1 ed, Econobook. Crítica Literaria. Barcelona: Gedisa.

Steiner, Rolando, y Universidad Nacional Autonoma de Nicaragua, 1958, Antígona En El Infierno. [Managua]: Universidad Nacional.

Walsh, Rodolfo J., y Alberto Adellach, 1981, Rodolfo Walsh Secuestrado Por La Junta Militar Argentina. 1 ed, Serie De Los Trabajadores De La Cultura Represaliados En Argentina. Madrid: Ediciones del Rescate.

Watanabe, Jose, y Marco Martos, 2000, Antígona: Versión Libre De La Tragedia De Sofocles. 1 ed. Lima: Comisión de Derechos Humanos. 